\title{
Is erythropoietin an acceptable treatment modality for routine use in preventing anaemia of prematurity?
}

\author{
S I Samarasekara ${ }^{1}$, Medha Weerasekara ${ }^{2}$ \\ Sri Lanka Journal of Child Health, 2011; 40(4): 159-163
}

\begin{abstract}
Objectives: To find out whether routine use of erythropoietin (EPO) would reduce transfusion requirements in infants $<1.5 \mathrm{~kg}$ and/or $<32$ weeks at birth and compare haemoglobin and reticulocyte counts of EPO treated and untreated groups.
\end{abstract}

Methods: Seventy eight infants were randomized. Cases received subcutaneous EPO 300 units $/ \mathrm{kg}$ /day, thrice weekly starting before 72 hours of birth for 14 days. All infants were given oral iron and folic acid with initiation of enteral feedings and this was continued during the entire treatment period.

Results: EPO treated group acquired high reticulocyte counts earlier than control group with maximal difference in 2 nd week but there was no statistically significant difference between groups. There was a gradual decline in haemoglobin values in both cases and controls; though this was less marked in the EPO treated group, the difference was not statistically significant. There was no statistically significant difference in total transfusion requirements between infants who received EPO and the control group.

Conclusion: There is no benefit from routine use of EPO during the first two weeks of life in preventing anaemia of prematurity.

(Key words: Erythropoietin; EPO; anaemia of prematurity; haemoglobin; reticulocyte count)

\section{Introduction}

Neonatology is a growing subspecialty in Sri Lanka and a large number of extremely premature/very low birth weight babies are being managed in neonatal intensive care units (NICUs) all over the country. Extremely low birth weight (ELBW) infants are exposed to frequent drawing of blood. These infants develop anaemia of prematurity (AOP), additionally by inadequate production of erythropoietin (EPO). Treatment of AOP includes

\footnotetext{
${ }^{1}$ Acting Consultant Neonatologist Teaching Hospital, Kandy, ${ }^{2}$ Consultant Neonatologist, Sri Jayewardenepura General Hospital, Kotte
}

(Received on 26 November 2010: Accepted on 17 January 2011) red blood cell transfusions, which are given to preterm infants based on indications ${ }^{1}$.

Transfused infants generally receive several packed cell transfusions during their hospital stay. Transfusions are given as and when required by low haemoglobin $(\mathrm{Hb})$ and the practice of single donor transfusion is not possible in most centres; babies are exposed to different donor samples and hence multiple sensitisations, in addition to the related risk of infection.

Anaemia of the premature baby is known to be contributed to by the lack of EPO to a larger extent rather than by deficiency of raw material needed for erythropoiesis ${ }^{2}$. EPO is an accepted mode of treatment for anaemia associated with extreme prematurity $^{3,4}$ but there is no strong evidence to support or reject the routine administration of erythropoietin in $\mathrm{AOP}^{5}$. We designed this study to see whether this practice is suitable to our country.

\section{Objectives}

1. To find out whether the routine use of EPO in the first two weeks of life would reduce the transfusion requirement of babies with birth weights $<1500 \mathrm{~g}$ and/or gestational age less than 32 weeks

2. To compare the $\mathrm{Hb}$ and reticulocyte counts of the EPO treated group with the untreated group.

\section{Method}

A prospective case control study was carried out on infants born at Sri Jayewardenepura General Hospital (SJGH) from $1^{\text {st }}$ November 2006 to $31^{\text {st }}$ October 2007 with birth weights $<1500 \mathrm{~g}$ and/or gestational age $<32$ weeks in whom maternal consent was obtained. Babies with major congenital malformations, chromosomal anomalies, haemolytic disease, haemorrhagic disease, intrauterine infections and systemic hypertension were excluded from the study. Infants were allocated randomly to treatment and control groups according to last 2 digits of the admission register.

The treatment group (cases) received EPO (300 units/kg/day, thrice weekly, subcutaneously) during first 14 days of life, starting before 72 hours 
of birth. All infants (cases and controls) were given oral iron $(6 \mathrm{mg} / \mathrm{kg} / \mathrm{day} \text {, as ferrous sulphate })^{6}$ and folic acid ( $2 \mathrm{mg} /$ day) starting when enteral feeding was initiated and continuing during the entire treatment period. Indications for transfusions followed a set of transfusion criteria laid down by authors after a lengthy literature review ${ }^{7}$ (Table 1) and the same criteria were used as a unit protocol. Patients were transfused with packed red blood cells at $20 \mathrm{ml} / \mathrm{kg}$, administered over 3 to 4 hours.

Table 1

Transfusion criteria

A) $\mathrm{Hb} \mathrm{10-12} \mathrm{mg} / \mathrm{dl}$

Receiving $>35 \%$ supplemental hood oxygen

On CPAP or mechanical ventilation with mean airway pressure $>6-8 \mathrm{~cm} \mathrm{H}_{2} \mathrm{O}$

B) $\mathrm{Hb}$ 6-10 $\mathrm{mg} / \mathrm{dl}$

Receiving $<35 \%$ supplemental hood oxygen

On CPAP or mechanical ventilation with mean airway pressure $<6 \mathrm{~cm} \mathrm{H}_{2} \mathrm{O}$

Significant apnoea and bradycardia ( $>9$ episodes in 12 hours or 2 episodes in 24 hours requiring bag and mask ventilation) while receiving therapeutic doses of methylxanthines

Heart rate $>180$ beats/min or respiratory rate $>80$ breaths/ min persisting for 24 hours

Weight gain $<10 \mathrm{~g} /$ day observed over 4 days while receiving $>100 \mathrm{kcal} / \mathrm{kg} / \mathrm{day}$

Undergoing surgery

C) $\mathrm{Hb} 6 \mathrm{mg} / \mathrm{dl}$ or less

Asymptomatic with reticulocytes $<1 \%$

D) Transfuse at any haematocrit value if hypovolaemic shock develops

E) Do not transfuse

To replace blood removed for laboratory tests

For low $\mathrm{Hb}$ alone

Respiratory rate, heart rate, blood pressure, number of apnoeic episodes, weight gain, and neurologic status were recorded daily. Total volume of blood withdrawn and the number and volume of blood transfusions were recorded daily from birth to 8 weeks. Laboratory monitoring included full blood count with reticulocyte and platelet counts twice weekly and weekly liver and renal function tests. All infants were followed up for at least 6 months after discharge from the hospital. The trial was approved by ethics and medical education committees of the Sri Jayewardenepura General Hospital. Parents gave written informed consent before entering infants into the protocol. Data was analyzed by stat direct software using student $\mathrm{T}$ test.

\section{Results}

During the study period the total number of babies born at SJGH with birth weights $<1500 \mathrm{~g}$ and/or gestational age $<32$ weeks was 106 . Seven patients (1 chromosomal abnormality, 1 major congenital malformation, 1 haemorrhagic disease and 3 haemolytic disease) were excluded from the study. Of the 99 babies eligible for enrolment maternal consent was obtained in 88 . Two babies were voluntarily taken out of study by the mothers. Eight babies died before completing the study (4 died of respiratory distress associated with extreme prematurity, 2 died of sepsis, 2 died of perinatal asphyxia). Seventy eight infants remained available for the final analysis. The characteristics of the 78 study infants are shown in Table 2.

Table 2

Characteristics of the study infants

\begin{tabular}{|l|c|c|c|}
\hline & Cases & Controls & P value \\
\hline Number \& sex & $38(18$ females $)$ & $40(19$ females $)$ & \\
\hline Mean GA (wks) & $29.2(\mathrm{SD}=3.1)$ & $27.4(\mathrm{SD}=3.3)$ & 0.97 \\
\hline Mean BW $(\mathrm{g})$ & $1.27(\mathrm{SD}=0.34)$ & $1.17(\mathrm{SD}=0.36)$ & 0.93 \\
\hline Survival on discharge & $35(92 \%)$ & $36(90 \%)$ & \\
\hline Prenatal steroids & $30(79 \%)$ & $33(82.5 \%)$ & \\
\hline Respiratory distress syndrome & $21(55 \%)$ & $21(52.5 \%)$ & \\
\hline Intraventricular haemorrhage & $8(21 \%)$ & $7(17.5 \%)$ & \\
\hline Retinopathy of prematurity & $1(2.6 \%)$ & $1(2.5 \%)$ & \\
\hline
\end{tabular}

The volume of phlebotomy losses and transfusion requirement throughout the study were analysed. There was no statistically significant difference

between infants who received EPO and the control group (Table 3). 
Table 3

Phlebotomy losses and transfusion requirement

\begin{tabular}{|l|c|c|c|}
\hline & Cases & Controls & P value \\
\hline Number & $38(18$ females $)$ & $40(19$ females $)$ & \\
\hline Number transfused & $17(44.7 \%)$ & $20(50 \%)$ & 0.91 \\
\hline $\begin{array}{l}\text { Mean transfusion volume } \\
\text { patient }(\mathrm{ml} / \mathrm{kg}) ;\end{array}$ & $46(\mathrm{SD}=6.7)$ & $47.2(\mathrm{SD}=13.4)$ & 0.92 \\
\hline Phlebotomy losses $(\mathrm{ml} / \mathrm{kg}) ;$ & $40(\mathrm{SD}=12.2)$ & $37(\mathrm{SD}=13.8)$ & \\
\hline
\end{tabular}

All transfusions administered met transfusion criteria. The total transfusion requirement was the same for both groups. No differences in the number of infants transfused, number of transfusions per infant, or volume of packed erythrocytes transfused between groups could be demonstrated. The total transfusion requirements were $4.4 \pm 1.7$ and $6.4 \pm 3.5$ transfusions per infant for the cases and controls respectively. Figure 1 shows the variation of haematological values during the first 8 weeks of age.

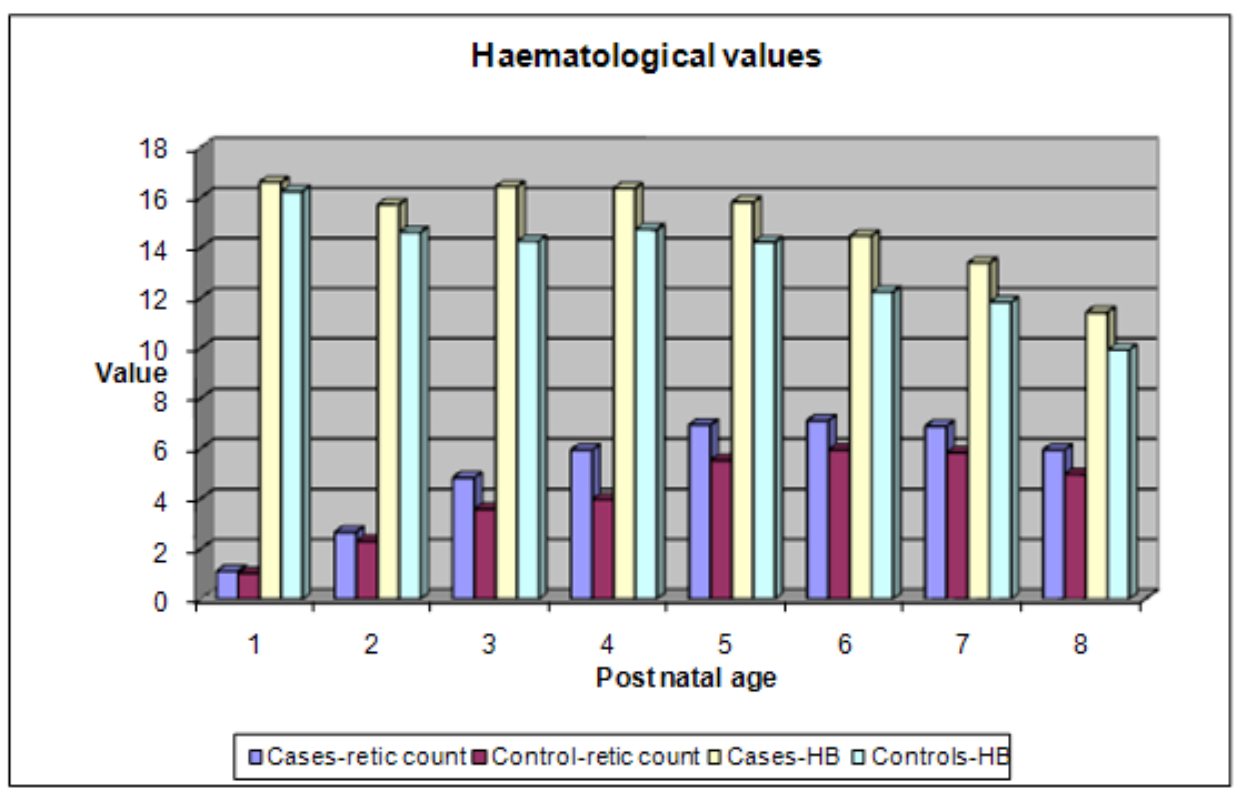

Figure 1: Haematologic values

EPO treated group acquired high reticulocyte count earlier than control group with maximal transient difference in the second week (Table 4 ) but by 8 weeks the gap was narrowed. There was no overall statistically significant difference in reticulocyte count between cases and controls.

Table 4

Reticulocyte counts in the infants

\begin{tabular}{|l|c|c|c|c|c|}
\hline & \multicolumn{2}{|c|}{ Reticulocyte count in Cases } & \multicolumn{2}{c|}{ Reticulocyte count in Controls } & P Value \\
\hline & Mean & SD & Mean & SD & \\
\hline Day 1 & 1.11 & 0.32 & 1.02 & 0.11 & 0.99 \\
\hline Day 3 & 2.66 & 1.78 & 2.30 & 1.36 & 0.99 \\
\hline Day 7 & 4.83 & 1.42 & 3.58 & 1.85 & 0.28 \\
\hline 2 Weeks & 5.94 & 1.16 & 3.97 & 2.33 & 0.22 \\
\hline 3 Weeks & 6.94 & 1.30 & 5.52 & 1.90 & 0.25 \\
\hline 4 Weeks & 7.11 & 1.32 & 5.94 & 2.14 & 1.23 \\
\hline 6 Weeks & 6.88 & 1.39 & 5.83 & 1.74 & 2.67 \\
\hline 8 Weeks & 5.94 & 1.17 & 4.97 & 1.91 & 2.41 \\
\hline
\end{tabular}

$\mathrm{Hb}$ values showed a gradual decline in both cases and controls. $\mathrm{Hb}$ values in cases were always high but the difference was not statistically significant. (Table 5) 
Table 5

Haemoglobin values in the infants

\begin{tabular}{|l|c|c|c|c|c|}
\hline & \multicolumn{2}{|c|}{ Haemoglobin in cases } & \multicolumn{2}{c|}{ Haemoglobin in controls } & P Value \\
\hline & Mean & SD & Mean & SD & \\
\hline Day 1 & 16.60 & 2.60 & 16.24 & 2.91 & 0.99 \\
\hline Day 3 & 15.71 & 2.10 & 14.62 & 2.28 & 0.97 \\
\hline Day 7 & 16.42 & 2.07 & 14.26 & 3.19 & 0.61 \\
\hline 2 Weeks & 16.36 & 1.74 & 14.72 & 2.11 & 0.95 \\
\hline 3 Weeks & 15.81 & 1.38 & 14.22 & 1.92 & 0.95 \\
\hline 4 Weeks & 14.46 & 2.15 & 12.23 & 3.49 & 0.96 \\
\hline 6 Weeks & 13.38 & 1.39 & 11.83 & 1.97 & 0.78 \\
\hline 8 Weeks & 11.42 & 1.16 & 9.933 & 1.69 & 0.84 \\
\hline
\end{tabular}

Oral iron administration was started at $9.4 \pm 3.0$ days in the cases and at $9.3 \pm 2.7$ days in the control group. The infants in the 2 groups had equivalent caloric intakes and rates of growth. The weight gain during the study was similar for both groups (Table 6). The mean weights at the end of treatment were $1263 \pm 204 \mathrm{~g}$ and $1171 \pm 192 \mathrm{~g}$ respectively.

Table 6

Weight gain during the study

\begin{tabular}{|l|c|c|c|c|c|}
\hline & \multicolumn{2}{|c|}{ Weight gain in Cases } & \multicolumn{2}{c|}{ Weight gain in Controls } & P Value \\
\hline & Mean & SD & Mean & SD & \\
\hline Day 1 & 1.27 & 0.18 & 1.17 & 0.16 & 0.95 \\
\hline Day 3 & 1.21 & 0.18 & 1.13 & 0.19 & 0.87 \\
\hline Day 7 & 1.22 & 0.21 & 1.13 & 0.22 & 0.86 \\
\hline 2 Weeks & 1.26 & 0.20 & 1.17 & 0.19 & 0.78 \\
\hline 3 Weeks & 1.37 & 0.28 & 1.29 & 0.28 & 0.89 \\
\hline 4 Weeks & 1.56 & 0.34 & 1.47 & 0.33 & 0.76 \\
\hline 6 Weeks & 1.85 & 0.38 & 1.72 & 0.43 & 0.84 \\
\hline 8 Weeks & 2.44 & 0.43 & 2.30 & 0.43 & 0.79 \\
\hline
\end{tabular}

No clinical adverse effects attributable to EPO, oral iron, or folic acid administration were observed. No case of sudden infant death was reported after discharge.

\section{Discussion}

There is a high level of erythropoiesis in the growing fetus ${ }^{8}$. In utero relative hypoxia results in a relatively high haematocrit and predominant synthesis of $\mathrm{HbF}$, with EPO produced in the liver regulating erythropoiesis. At birth fetal EPO concentration is high but declines progressively thereafter. In preterm infants the expected postnatal decline in $\mathrm{Hb}$ is more prolonged and pronounced than in full-term infants and the premature infants may become anaemic. Some studies have shown that EPO given to infants with anaemia of prematurity produced an earlier increase in reticulocyte counts compared with placebo; however, the difference between groups was not significant ${ }^{9}$. EPO therapy did not suppress subsequent release of endogenous EPO. It is suggested that a higher dose of EPO may be required to treat anaemic premature infants ${ }^{10}$.

Very low birth weight (VLBW) infants are one of the main groups of patients requiring red blood cell transfusions. Sixty percent to $100 \%$ of VLBW infants receive multiple transfusions, mostly during the first 2 weeks of life ${ }^{10}$. The combination of EPO and oral iron stimulates erythropoiesis in preterm infants resulting in fewer transfusions during their early weeks of life ${ }^{3}$. The use of EPO during this period, when anaemia results predominantly from the amount of blood sampled for laboratory tests, has not been adequately evaluated. A few published trials have suggested its usefulness, but the interpretation of these results remains controversial $^{11}$. There is limited data available on EPO and oral iron in the very early neonatal period as well as the bone marrow response ${ }^{12}$.

In our study, the EPO administration was associated with higher reticulocyte counts and haematocrits compared with controls. However, this response was not sufficient to decrease the need for transfusion; the number of transfusions received as well as the total transfusion requirement was similar for both groups. However, EPO can be used as a mode of treatment in selected cases e.g. Jehovah witness ${ }^{13}$. In these cases low transfusion requirement can be achieved by combination of several methods: 1) use of EPO 2) adherence to very strict transfusion criteria 3) minimising the 
number of routine blood tests and 4) early iron treatment.

We started oral iron and folic acid as soon as enteral feedings were initiated ${ }^{14}$. There were no clinical adverse effects to iron administration. Therefore, we believe that our protocol for early oral haematinic supplementation is adequate to support a response to EPO. Some reports suggest that rarely thrombocytopenia and neutropenia could occur with $\mathrm{EPO}^{15}$ but this was not a feature in our study.

\section{Conclusion}

There is no benefit from routine administration of EPO to preterm infants during the first two weeks of life in preventing anaemia of prematurity.

\section{References}

1. Bishara N, Ohls RK. Current controversies in the management of the anaemia of prematurity. Semin Perinatol. 2009; 33(1):29-34. http://dx.doi.org/10.1053/j.semperi.2008.10.006

2. Moritz KM, Lim GB et al. Developmental regulation of erythropoietin and erythropoiesis; Am J Physiol Regul Integr Comp Physiol 1997; 273 (6): 1829-44.

3. Halperin DS, Felix M, Wacker P,et al . Recombinant human erythropoietin in the treatment of infants with anaemia of prematurity. European Journal of Pediatrics 1992; 151:661-7.

http://dx.doi.org/10.1007/BF01957568

4. Ohls RK, Harcum J, Schibler KR. The effect of erythropoietin on the transfusion requirements of preterm infants: A randomized, double-blind, placebo-controlled study. The Journal of Pediatrics 1997; 131 (5): 661-5.

http://dx.doi.org/10.1016/S0022-3476(97)70089-1

5. Bechensteen AG, Haga $P$, Halvorsen $S$, Whitelaw A. Erythropoietin and iron supplementation and the prevention of anaemia of prematurity. Archives of Disease in Childhood 1993; 69: 19-23. http://dx.doi.org/10.1136/adc.69.1_Spec_No.19

6. Siva Subramanian KN. Extremely Low Birth Weight Infant. Available from:

http://www.emedicine.com/ped/topic2784.htm
7. Fetus and Newborn Committee, Canadian Paediatric Society. Red blood cell transfusions in newborn infants [Revised guidelines]. Paediatrics \& Child Health 2002; 7(8):553-8.

8. Finne PH, Halvorsen S. Regulation of erythropoiesis in the fetus and newborn. Arch Dis Child 1972; 47 (255): 683-7. http://dx.doi.org/10.1136/adc.47.255.683

9. Phibbs RH, Shannon KM, Mentzer WC. Potential for treatment of anaemia of prematurity with recombinant human erythropoietin. Acta Haematol 1992; 87; 2833. http://dx.doi.org/10.1159/000204786

10. Maier RF, Obladen M, Messinger D. Factors related to transfusion in very low birth weight infants treated with erythropoietin; Arch Dis Child Fetal Neonatal Ed 1996; 74(3): 182-6. http://dx.doi.org/10.1136/fn.74.3.F182

11. Ohlsson A, Aher SM. Early erythropoietin for preventing red blood cell transfusion. Cochrane Database of Systematic Reviews 2006, Issue 3. Art. No.CD004863.

12. Widness JA. Pathophysiology, diagnosis, and prevention of neonatal anaemia. Pediatrics in Review Neo Reviews. 2000; 1:e61-e68.

13. Schalte G, Janz H. Life-threatening postoperative blood loss in a Jehovah's Witness, treated with high-dose erythropoietin. Br. J. Anaesth 2005; 94 (4): 442-4. http://dx.doi.org/10.1093/bja/aei068

14. Ridley FC, Harris J, Gottstein R, Emmerson AJB. Is supplementary iron useful when preterm infants are treated with erythropoietin? Arch Dis Child 2006; 91(12): 1036-8. http://dx.doi.org/10.1136/adc.2006.105205

15. Loo M, Beguin Y. The effect of recombinant human erythropoietin on platelet counts is strongly modulated by the adequacy of iron supply. Blood 1999; 93: 3286-93. 